\title{
Change of lipid profile in shift workers in western Odisha
}

\author{
Arpita Priyadarshini*, R.K Nanda**, R.V Hemamalini*** \\ ${ }^{*}$ Associate Professor, ${ }^{* *}$ Assistant Professor, ${ }^{* * *}$ Post Graduate Dept.Of Physiology, V.S.S Medical College , Burla
}

Indian J Sleep Med $2011 ; 6.3,97-101$

\begin{abstract}
Almost all occupations or industries have employees engaged in shift work. Shift work has been associated with a number of health problems including cardiovascular disease, glucose and lipid metabolism, gastrointestinal, reproduction difficulties, and breast cancer.

Number of persons doing shift work appears to be increasing. It ranges from $10-25 \%$ of all those employed. To study the effect of night shift work on lipid profile in industrial workers at Burla, a study was conducted in day workers $(n=50)$ and night shift workers $(n=50)$. The end points were increase in serum total cholesterol, increase in LDL, VLDL, decrease in HDL from baseline during the period of observation. The association between shift work and lipid disorders was investigated adjusting for age, body mass index. Study among the industrial workers revealed that night shift work was a significant independent risk factor for lipid disorder.
\end{abstract}

Keywords: shift work, total cholesterol, triglycerides, HDL, LDL,VLDL

\section{Introduction}

W estern Odisha is undergoing rapid industrialization because of which life style is changing Particularly the circadian rhythm of the body by mode of shift work. This new environment is virgin to this part of the country so we can correlate the recent changes in the lipid profile and the shift work pattern. As deranged lipid profile is common for the pathogenesis of atherosclerosis, coronary artery disease,sudden cardiac death and strokes.

This study is done to see whether shift work is a danger to sustain normal physiological parameters.

Broadly defined, shift work involves work at times

Address for correspondence

Dr Arpita Priyadarshini

Associate Professor

Dept.Of Physiology, V.S.S Medical College, Burla other than normal daylight hours of approximately 7:00 A.M, to 6:00 P.M. Number of persons doing shift work appears to be increasing. It ranges from 10$25 \%$ of all those employed. ${ }^{1}$ In normal individuals living on a day-oriented schedule, it is hypothesized that a harmonious relationship between homeostatic and circadian processes serves to promote an uninterrupted bouts of $8 \mathrm{~h}$ of sleep and $16 \mathrm{~h}$ of wakefulness per day. When sleep is displaced, the normal phase relationship between the sleep/wake cycle and the endogenous circadian pacemaker is disturbed, which can lead to substantial deterioration in sleep quality and duration. ${ }^{2}$ As a result, day sleep in shift workers is often measured as $1-3 \mathrm{~h}$ shorter than night sleep on days off, or on day and evening work schedules. Working on irregular schedules can involve acute sleep disruption in the form of extended waking episode (often just preceding a first night shift), in addition to chronic sleep disruption resulting from circadian misalignment to the sleep/wake schedule. 
Ralph et $\mathrm{al}^{3}$ in 1990 discovered that the "suprachiasmatic nucleus" is the site of primary regulation of circadian rhythmicity in mammals. Reinberg A et $\mathrm{al}^{4}$ in 1992 demonstrated lipid profile disturbances related to circadian rhythm disruption caused by shift work.

\section{Material and methods}

The study was conducted on an outpatient basis at Department of Physiology, V.S.S Medical college, Burla with the help of Department of Biochemistry.

The material includes workers of MCL undergoing shift duties. Fifty were night shift workers who shift worked for atleast 1 year. Fifty day workers were taken as control who did not undergo night shift for atleast previous 5 years.

Shift work was defined as work at times other than normal daylight hours of approximately 7:00 AM to 6:00 PM. For night shift workers, work schedule is from 10:00 PM to 6:00 AM and for day workers it is from 6:00 AM to 2:00 PM.The night shift work involved operating various machines and correcting errors either manually or by computer.

Informed consent was obtained from all volunteers after oral and written information had been given.

Subjects filled out a questionnaire with questions about working condition, smoking habits, diet, family history of hypertension, diabetes mellitus, dyslipidemia and hypothyroidism. Bloodpressure, height, weight, BMI of all subjects were recorded before the collection of blood.

Blood pressure was measured in the sitting position after 5 minutes rest. Hypertension was defined as having a systolic blood pressure of $140 \mathrm{mmHg}$ or more, or a diastolic blood pressure of $90 \mathrm{mmHg}$ or more and answering yes about being on antihypertensive medication. Body weight was measured in light indoor clothing and recorded to the nearest Kg. Height was measured to the nearest centimeter without shoes. Body mass index (BMI) was calculated as weight $(\mathrm{Kg})$ divided by height $(\mathrm{m} 2)$. Those with a BMI of 30 or more were classified as obese.

\section{Exclusion criteria}

Subjects with following conditions were excluded in the study-subjects suffering from any endocrine, hepatic, renal disease, hypertension, diabetes, cardiopulmonary disease, history of drug intake-beta blockers, lipid lowering drugs, alcohol intake, obese were excluded from the study.

\section{Selected cases}

Only males within the age group of 25-40 were involved in the study. No females were involved in the study group. Individuals more than 40 years were not included as increased age groups are risk factors for increased cholesterol levels.

\section{Sample collection}

Venous blood samples were collected in a sterile bottle without anticoagulant and allowed to clot. The serum was analysed for lipid profile.

Serum total cholesterol, Triglycerides, LDL, VLDL and HDL-cholesterol concentration were estimated after 12-hours fasting by using auto analyzer. Triglyceride value $>150 \mathrm{mg} / \mathrm{dl}$, HDL-cholesterol $<45 \mathrm{mg} / \mathrm{dl}$, cholesterol $>200 \mathrm{mg} / \mathrm{dl}$, LDL $>130 \mathrm{mg} / \mathrm{dl}$ were defined as lipid disturbances.

\section{Statistical analysis}

Analysis of data was done with the help of computer by SPSS program version of 12.0 soft ware facilities.

unPaired t test was done. P value $<0.05$ is considered significant.

\section{Observations}

Table 1: Age distribution of shift workers \& day workers

\begin{tabular}{|l|l|l|}
\hline Age Group (in years) & Shift Workers & Day workers \\
\hline $26-30$ & 25 & 25 \\
\hline $31-35$ & 15 & 15 \\
\hline $36-40$ & 10 & 10 \\
\hline
\end{tabular}

Table 1 represents a brief age group of shift workers and day workers. Major proportion of the shift workers belong to $25-30$ years. Age groups more than 40 years were not considered as advancing age group would be a risk factor for deranged lipid profile. 
Table 2: BMI of shift workers $\&$ day workers

\begin{tabular}{|l|c|c|}
\hline BMI & Shift Workers & Day workers \\
\hline $18.9-20.9$ & $18 \%$ & $10 \%$ \\
\hline $20.9-22.9$ & $35 \%$ & $23 \%$ \\
\hline $22.9-24.9$ & $47 \%$ & $67 \%$ \\
\hline
\end{tabular}

Table 2 represents a Body mass index of shift workers and day workers. BMI is calculated by:

BMI $=\underline{\text { Height in } \mathrm{m}^{2}}$

Weight in $\mathrm{Kg}$

Individuals with BMI $<25$ were considered for the study to avoid BMI as a confounding factor for deranged lipid profile.

Table 3: Estimation of serum lipid

\begin{tabular}{|l|l|l|l|}
\hline $\begin{array}{l}\text { Serum } \\
\text { lipid } \\
\text { mg/dL }\end{array}$ & Shift workers & Day workers & PValue \\
\hline TC & $210.38 \pm 2.30$ & $180.10 \pm 33.15$ & $\begin{array}{l}<0.01 \\
\text { significant }\end{array}$ \\
\hline TG & $150.12 \pm 56.90$ & $150.0 \pm 52.30$ & $\begin{array}{l}>0.05 \\
\text { insignificant }\end{array}$ \\
\hline VLDL & $49.9 \pm 20.30$ & $30.6 \pm 21.20$ & $\begin{array}{l}<0.05 \\
\text { significant }\end{array}$ \\
\hline LDL & $133.38 \pm 57.80$ & $100.4 \pm 32.30$ & $\begin{array}{l}<0.05 \\
\text { significant }\end{array}$ \\
\hline HDL & $35.48 \pm 5.88$ & $44.30 \pm 5.03$ & $\begin{array}{l}<0.05 \\
\text { significant }\end{array}$ \\
\hline
\end{tabular}

Table 3 represents estimation of serum lipid. Total cholesterol, very low density lipoprotein, low density lipoprotein levels increased significantly but high density lipoprotein level decreased significantly and Triglyceride level showed no significant change among shift workers. Day shift workers did not show significant change in serum lipid.

\section{Discussion}

This study showed that high serum total cholesterol, LDL, VLDL were more common in shift workers than in day workers. This finding persisted after adjustment was made for age and food type. The results are in agreement with the results in previous studies. But other studies have shown that there was no difference in serum total cholesterol between shift workers and day workers.

Lennernas et $\mathrm{al}^{5}$ documented that dietary intake is lower during night shift than during morning and

\begin{tabular}{|l|l|l|l|l|l|}
\hline & SWDW & N & Mean & $\begin{array}{l}\text { Std. } \\
\text { Deviation }\end{array}$ & $\begin{array}{l}\text { Std. Error } \\
\text { Mean }\end{array}$ \\
\hline TC & SW & 50 & 239.7600 & 18.96351 & 2.68185 \\
\hline & DW & 50 & 180.1000 & 6.31568 & .89317 \\
\hline
\end{tabular}

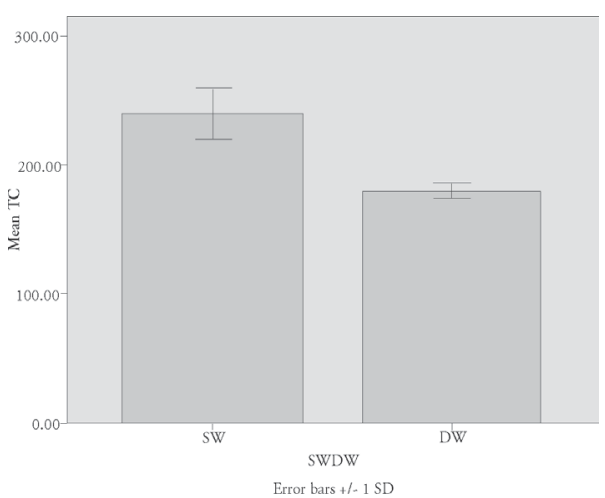

\begin{tabular}{|l|l|l|l|l|l|}
\hline & SWDW & N & $\begin{array}{l}\text { Mean } \\
\text { Deviation }\end{array}$ & $\begin{array}{l}\text { Std. } \\
\text { Mean }\end{array}$ & Std. Error \\
\hline TG & SW & 50 & 149.9000 & 3.29037 & .46533 \\
\hline & DW & 50 & 146.5800 & 4.48166 & .63380 \\
\hline
\end{tabular}

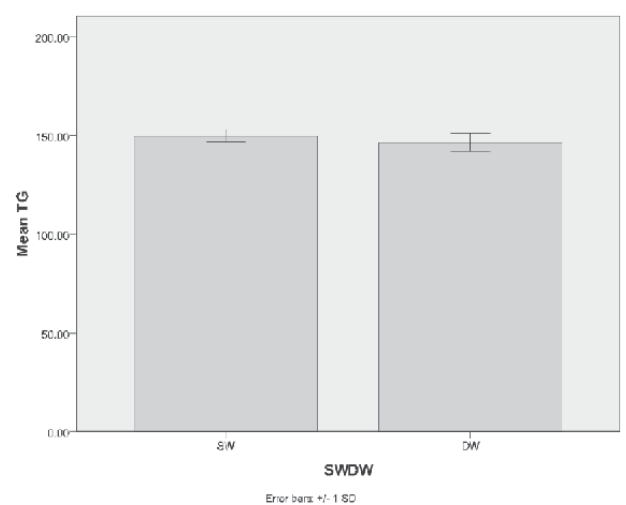

\begin{tabular}{|l|l|l|l|l|l|}
\hline & SWDW & $\mathbf{N}$ & $\begin{array}{l}\text { Mean } \\
\text { Deviation }\end{array}$ & $\begin{array}{l}\text { Std. } \\
\text { Mean }\end{array}$ & Std. Error \\
\hline VLDL & SW & 50 & 41.2600 & 6.45490 & .91286 \\
\hline & DW & 50 & 30.6000 & 5.07495 & .71771 \\
\hline
\end{tabular}

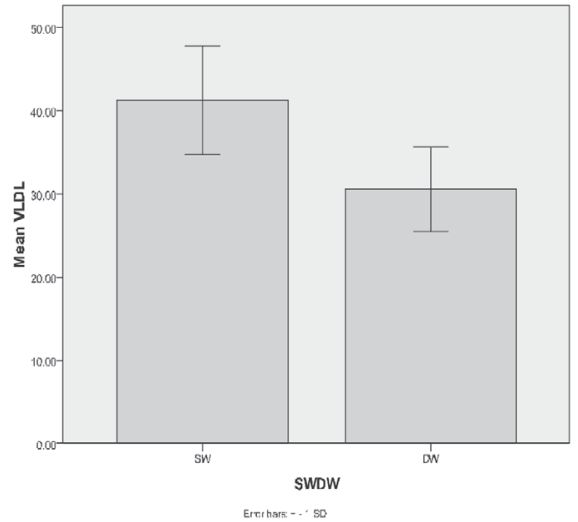

Indian Journal of Sleep Medicine (IJSM), Vol. 6, No. 3, 2011 


\begin{tabular}{|l|l|l|l|l|l|}
\hline & SWDW & N & Mean & $\begin{array}{l}\text { Std. } \\
\text { Deviation }\end{array}$ & $\begin{array}{l}\text { Std. Error } \\
\text { Mean }\end{array}$ \\
\hline LDL & SW & 50 & 137.5600 & 5.59212 & .79085 \\
\hline & DW & 50 & 100.4000 & 10.82514 & 1.53091 \\
\hline
\end{tabular}

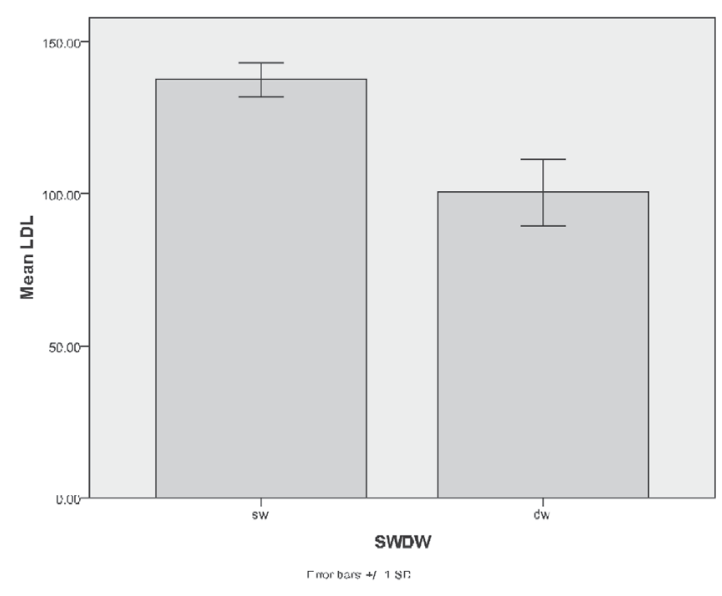

\begin{tabular}{|l|l|l|l|l|l|}
\hline & SWDW & N & Mean & $\begin{array}{l}\text { Std. } \\
\text { Deviation }\end{array}$ & $\begin{array}{l}\text { Std. Error } \\
\text { Mean }\end{array}$ \\
\hline HDL & SW & 50 & 36.1000 & 2.54149 & .35942 \\
\hline & DW & 50 & 44.3600 & 2.55359 & .36113 \\
\hline
\end{tabular}

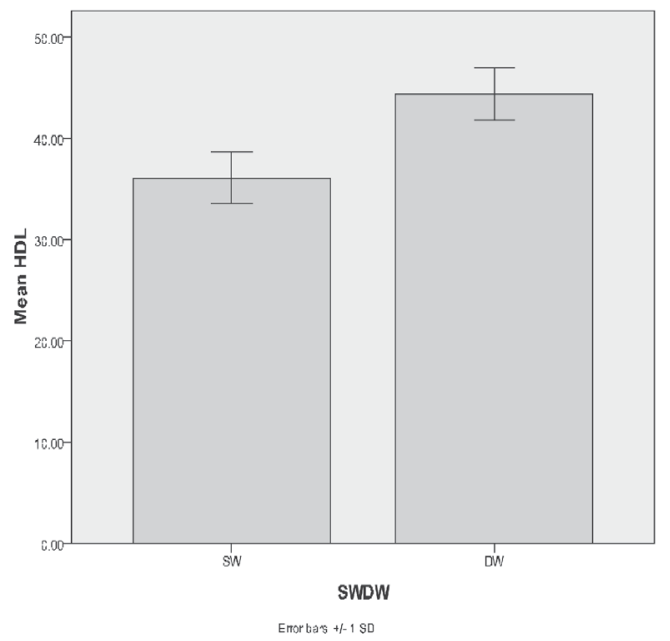

afternoon shifts. According to them, the redistribution of food intake from diurnal eating to nocturnal eating is related to serum total cholesterol, LDL- cholesterol. Even if the dietary intake and quality are similar in day workers as well as shift workers, there are still differences in eating habits that might contribute to differences in levels of serum lipids.

The amount of carbohydrates ingested in the night hours was associated to cholesterol levels, and it was suggested that this was due to an internal desynchronisation between eating and metabolism according to one study carried out by Knutsson et $\mathrm{al}^{6}$

There is no differences in the prevalence of triglyceride when comparing shift workers and day workers. But previous studies have been shown high serum triglyceride levels to be more prevalent among shift workers than the day workers .

Knutsson ${ }^{6}$ observed a slight increase of cholesterol and triglyceride levels in shift workers, which is an important observation considering that these and other lipids are the best markers of atherosclerotic diseases

In this study as the dietary pattern were not altered among night shift workers, triglyceride level remained within the normal range.

In this study, there is decrease in the prevalence of HDL-cholesterol level among night shift workers in comparison with day workers, so this results in agreement with the other studies which show low HDL-cholesterol serum level to be more prevalent between the shift workers than the day workers

Estimation of serum lipids were done yearly. The increase in total cholesterol at the end of second year of study was $2 \%$ more than the first year.

The number of years in shift work is some support to a dose-response in the sense of years on shift work. The study on Swedish papermill workers showed an almost linear relation between years in shift work and risk of lipid disturbances.

Also the studies by Tenkanen and Kawachi ${ }^{7}$ report dose-response between year in shift work and an increasing risk of cardiovascular morbidity due to altered lipid levels.

\section{Conclusion}

On the basis of this study, it is recommended that in every work place where shift work is mandatory, a chronoclinic should be established. Trained health care personnel of the chronoclinic should monitor intermittently (preferably every alternate year) the state of the biological clock (synchronized or desynchronized) of each shift worker. Upon discovering rhythm desynchronization his/her transfer from shift work to day work for at least one year should be recommended. This may improve the coping ability of shift workers thus minimizing the occupational health hazards and 
maximize their performance. This would substantially increase the productivity of the organization for which they are working.

\section{References}

1. Masoumeh Ghiasvand,Ramin Heshmat,Reza Golpira:shift work and risk of lipid disorders,Lipids in health and disease 2006;5:9

2. Pati AK, Chandrawshi A, Reinberg A. Shift work: consequence and management. Curr Sci.2002;81:32-47.

3. Ralph MR, Foster RG, Davis FC, Menaker M. Transplanted suprachiasmatic nucleus determines circadian period.
Science 1990;247:975-978.

4. Reinberg A, Motohashi $Y$, Bourdeleau $P$, et al: Internal desynchronization of circadian rhythms and tolerance of shiftwork. Chronobiologia 1992;16:21.

5. Lennernas $\mathbf{M}$, Akerstedt T, Hambraeus L. Nocturnal eating and serum cholesterol of three-shift workers. Scand J work Environ Health. 1994;20:401-406.

6. Knutsson A,Akersted T,Jonson BG et al: Increased Risk of ischemic heart disease in shift workers. Lancet 12, July: 1986; 12: 89.

7. Tenkanen L, Sjoblom TS, Kalimo R, et al: Shiftwork, occupation and coronary heart disease - over 6 years of follow-up in the Helsinki Heart Study. Scand J Work Environ Health 1986. 1997; 23: 257 